\title{
Student attrition in mathematics e-learning
}

\author{
Glenn Gordon Smith \\ University of South Florida \\ David Ferguson \\ Stony Brook University, New York
}

\begin{abstract}
Qualitative studies indicate that mathematics does not work well in elearning. The current study used quantitative methods to investigate more objectively the extent of problems with mathematics in e-learning. The authors used student attrition as a simple measure of student satisfaction and course viability in two studies, one investigating attrition in e-learning and a second comparison study of attrition in face to face courses. In elearning, attrition (drop out rate) was significantly higher for math courses versus non-math. For face to face courses, attrition rates for math versus non-math courses were nearly equal. The authors suggest reasons for high student attrition in math e-learning. Online student populations are different from their face to face peers. E-learning systems are poorly adapted to mathematics.
\end{abstract}

\section{Introduction}

Student attrition rates are higher in distance education and e-learning (web based asynchronous distance education) virtual courses than in traditional face to face courses (Thompson, 1997; Phipps \& Merisotis, 1999; Smith, Ferguson \& Caris, 2002). This is a persistent problem. Researchers have investigated student attrition or dropout in distance education and elearning in terms of student demographics such as age, maturity level, gender, marital status and educational level (Morgan \& Tam, 1999; Carr, 2000). Researchers have also found evidence that particular student characteristics increase the odds of a student finishing a course. Students who are self starters, self disciplined, knowledgeable in the e-learning format and comfortable interacting online with others are more likely to finish e-learning classes (Roblyer, 1999; Wade, 1999). Research has also suggested that the attrition rate may be lower in classes with instructors more experienced in e-learning (Carr, 2000). However there is little, if any research looking at attrition rates in e-learning courses by discipline. The 
current study examines student attrition in math versus non-math related courses, in both e-learning and face to face mode.

There has been an explosion of e-learning in the last ten years, making college courses available to new populations, such as people working full time, people living far from universities, commuter students and house bound parents, etc. (Shea, Swan, Fredericksen \& Pickett, 2001). Online instructors wax poetic over the new possibilities of e-learning, the increased one to one interaction with students, the deeper levels of discussion engendered by the written format, and increased student participation (Boshier, 1990; Swan, 2001; Smith, Ferguson \& Caris, 2002). But markedly missing from the celebration are online math instructors and students (Leventhall, 2004; Smith \& Ferguson, 2004; Smith, Ferguson \& Gupta, 2004). Online math instructors complain bitterly that text oriented online course management systems (CMS) do not provide adequate support for math notation, formulas and diagrams, the very language of math! In a needs assessment of web based math instructors in New York State (Smith, Ferguson \& Gupta, 2004), a typical response was, "It has been extremely frustrating teaching math online..."

Instructors participating in this needs assessment consistently complained that the common course management systems did not provide adequate support for math notation and diagrams, the very building blocks of math communication. In order to get math notation into online documents, instructors had to go through a three step process: 1) Use their word processor (Microsoft Word with a "plugin", WebEQ) to generate a file with math notation. 2) Save the word processed file as an image file. 3) Upload this image file as an attachment into their e-learning course. A similar three step process is required to put diagrams into online e-learning postings. This three step process for importing math notation into e-learning documents makes communication in online math courses extremely awkward. It is time consuming for instructors to put math notation in their postings. Generally students could not (and still can not) respond in kind with math notation and diagrams because: 1 ) they do not have the kinds of tools to generate math notation and diagrams, and 2) even when they have such tools, the learning curve for the tools, in addition to learning the basic e-learning environments, is overwhelming for many students (Leventhall, 2004; Smith, Ferguson \& Gupta, 2004). Therefore students and instructors in online math courses cannot communicate back and forth (two way) in math notation and formulas in a natural way. By contrast, in face to face math courses, chalkboard and paper and pencil make the two way communication of math notation relatively easy.

To address the problems of math notation and diagrams in e-learning, the current authors have directed a research project, MathThread (MathThread 
Partnership: Distance Learning and Outside of Class Collaboration for Math), funded by the National Science Foundation CCLI A\&I program award number 0126956. The research project, MathThread, has addressed the issues of math notation and diagrams in e-learning over the last three years, working towards a goal of seamless two way communication of math notation and diagrams in e-learning between instructors and students. There has been significant progress. MathThread has worked with LinkSystems to help them enhance their NetTutor Whiteboard to better support math notation and diagrams in online math courses. MathThread has conducted usability studies, faculty development seminars, and supported a number of pilot online math courses using these tools. NetTutor now supports two way communication of both math notation and diagrams. However it still has some significant usability problems. It is not easy or natural for students to learn and it has intermittent bugs. Moreover it is usually an add on to e-learning environments. It is often a burden for online students to learn another tool. Meanwhile other common course management systems, Blackboard and FirstClass, now incorporate WebEQ into their CMSs, supporting two way communication of math notation (but, alas, not diagrams). However WebEQ's user interface is very rigid and difficult for students to learn and use (Leventhall, 2004; Smith, Ferguson \& Gupta, 2004). Many online math courses do not have these tools (NetTutor, WebEQ) and still resort to attachments or other cumbersome processes. Those who do have these tools (NetTutor, WebEQ) find they leave much to be desired (Leventhall, 2004). The math notation and diagrams communication issues in e-learning remain unresolved.

Some of the work of the MathThread group is discussed in journal articles and conference proceedings, such as Smith (2005), Smith \& Ferguson (2004), Smith, Ferguson \& Gupta (2004), Smith \& Ferguson (2003) and Smith, Grackin, Ferguson \& Izubuchi (2002). The current paper and study is part of the MathThread research group work. The MathThread project is continuing its research.

Moreover the problems of online college math courses run much deeper than the support of math notation and diagrams. The current e-learning model which is asynchronous and relies heavily on threaded discussions does not work well for math. It is particularly challenging for the teaching and learning of mathematical problem solving (Smith \& Ferguson, 2004). Here is one representative instructor quote from a 2004 interview study (Smith \& Ferguson, 2004) on online teaching and learning of problem solving in math courses: "...online, math students tend to 'panic' with math problems and give up quickly." One typical online student said, "There is too much time in between contacts in distance learning, and the work suffers." 
The current authors and other researchers have uncovered substantial qualitative and anecdotal evidence on the difficulties of teaching and learning college mathematics in online environments. However qualitative research techniques (such as interview studies with a limited number of participants) do not generalise well. The current study uses quantitative research methods (inferential statistics) to investigate more objectively the extent of problems with math e-learning. It is also important to provide a comparison between e-learning and more traditional face to face courses. In other words, are the problems in teaching and learning mathematics (mentioned above) particular to e-learning, or are there comparable difficulties in traditional face to face courses? Therefore the research questions are: 1) How does mathematics compare to other disciplines in terms of viability in e-learning? 2) How does mathematics compare to other disciplines in terms of viability in more traditional face to face courses?

\section{Method}

Student attrition rate in e-learning is an important research tool for evaluation and assessment of e-learning courses (Phipps \& Merisotis, 2000). Therefore in the current study, we use attrition rate, the fraction of students who drop out of a course as a rough measure of difficulties in courses. If students find a course overwhelming, tedious, unmanageable, not what they expected, or an unpleasant experience, they will tend to drop or withdraw from that course. Some students may enroll in more classes than they intend to take, dropping the ones they like least. Nevertheless higher attrition rates indicate problems from the student point of view. The authors selected attrition rate as a simple and convenient quantitative indication of student satisfaction and course viability. To provide an effective comparison, the authors conducted two studies, one investigating attrition rates in online course and a second comparison study of attrition rates in face to face courses at a major research university.

In the first study, the authors conducted a survey of instructors of elearning courses, asking them specifically about attrition rates. Participants were online instructors teaching e-learning courses through the SUNY Learning Network (SLN), a non-profit organisation which supports over 3,000 e-learning courses to the more than 40 colleges in the State University of New York system. The rules of SLN are that courses are 100\% online and asynchronous, ie., that no graded assignments can be associated with either face to face meetings or synchronous chat sessions. Prior to online course development, instructors attend faculty orientations on course design. During development of their courses, SLN assigns to each online instructor a Multimedia Instructional Designer (MID) who looks over their course design. Therefore there is a high compliance to the rules that courses be $100 \%$ online and asynchronous. SLN courses are delivered using Lotus 
Notes as a course management system, which provides no specific support for mathematics. Many SLN math instructors supplement Lotus Notes with math oriented web sites supplied with their text book.

The authors' email survey of SLN instructors included three questions: 1) Is your online course math related? 2) What was the initial enrollment of your online course? 3) What was the final enrollment of your online course? This survey was sent very close to the end of the semester. Therefore "initial enrollment" should reflect enrollment after the initial drop/add period. With these three questions, the authors were able to compute the attrition rate (fraction of initial enrollment dropping a course) for math versus nonmath related courses. The authors used both: a) the title of the course (as found online) and b) the instructor's response as to whether it was math related, to triangulate on whether the course was math related. One hundred and thirty-eight online instructors responded to the email survey. Thirty-two of these instructors were teaching math or math related online courses. The sample involved both undergraduate and graduate courses.

In order to provide a comparison with face to face courses, the authors approached the Department of Institutional Research at Stony Brook University to obtain data for a second study. Stony Brook University is part of the State University of New York (SUNY) system of colleges and until recently was one of the universities making use of the SUNY Learning Network's e-learning services, mentioned in the first study.

The Department of Institutional Research at Stony Brook University provided data on attrition rates for all face to face courses offered in the College of Arts and Sciences for Fall 2003. The data included comparable values: 1) whether the course was math related, 2) Initial enrollment (following the initial no penalty drop-add period), and 3) final enrollment. The number of face to face courses involved in the second was 1,246, of which 57 were math or math related. This included both undergraduate and graduate courses.

Two major differences between the studies are worth discussing. One is that the sample sizes are quite different. According to standard inferential statistical techniques, as long as samples are random or representative of the larger population, a sample size of at least 30 for each group should provide a power of $80 \%$ which is the minimum for ordinary studies (Cohen, 1988). The sample sizes for all groups in this study are larger than 30. Secondly, the demographics of online students will no doubt be quite different from students in traditional face to face courses. Online students tend to be part time students holding down full time jobs. Students in traditional face to face courses tend to be younger full time students. Therefore we did not pool the data together in one study and make a direct 
comparison. However an implied comparison is made. We feel that differences in student demographics are part of the landscape. Authentic studies of e-learning and face to face teaching and learning must use representative populations.

\section{Results}

\section{Study one}

For online courses, the average attrition rate for math related courses was 0.31 . The standard deviation was 0.22 . For non-math related courses, the average attrition rate was 0.18 and the standard deviation was 0.14 . An analysis of variance, comparing the attrition rates for math and non-math related courses, indicated the difference was significant at the 0.001 level. Obtained significance was actually 0.0001 level $(F=16.6)$. Figure 1 and Table 1 show these results.

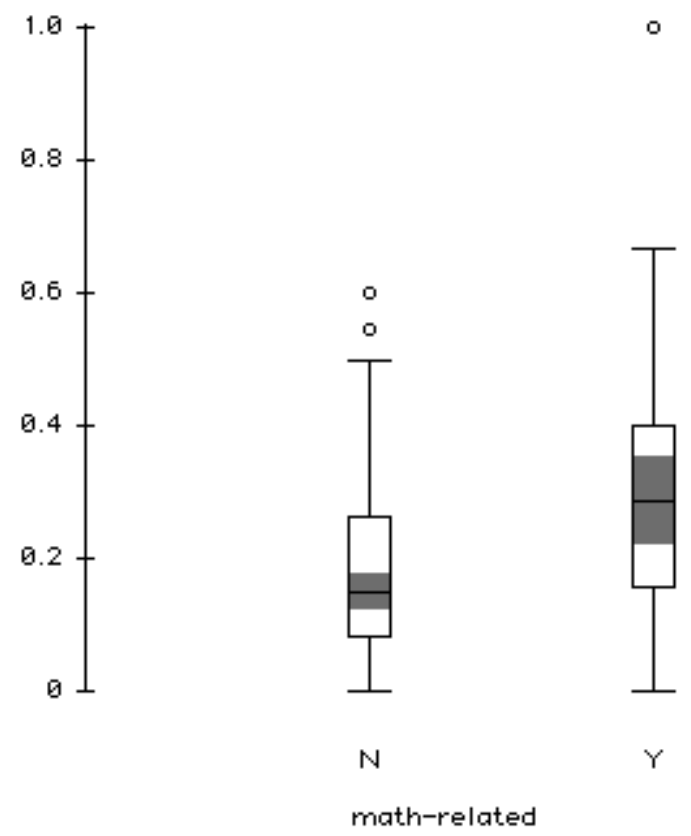

Figure 1: Box plot of attrition rates (the number of students who dropped out divided by the initial enrollment) for online courses for non-math related $(\mathrm{N})$ and math related $(\mathrm{Y})$ disciplines. 
Table 1: Attrition rates for online courses, math versus non-math

\begin{tabular}{|c|c|c|c|}
\hline Group & Count & Mean & Std dev \\
\hline Non-math & 106 & 0.18 & 0.14 \\
\hline Math & 32 & 0.31 & 0.22 \\
\hline
\end{tabular}

Figure 1 shows a box plot of the attrition rate data of online courses from study one. " $\mathrm{N}$ " and " $\mathrm{Y}$ " along the x-axis indicate whether "No" or "Yes" the data points are from math related courses. The vertical axis indicates the fraction of the initial enrollment which dropped out.

\section{Study two}

For the face to face courses, there were no significant differences between attrition rates for the math versus the non-math related courses. In fact, the attrition rates were nearly equal. For the math related face to face courses, the average attrition rate was 0.05 . For non-math courses, the average attrition rate was 0.05 . Standard deviations were 0.1 and 0.06 respectively. Table 2 shows the average attrition rates for face to face courses, and Figure 2 is a box plot of the attrition rate data.

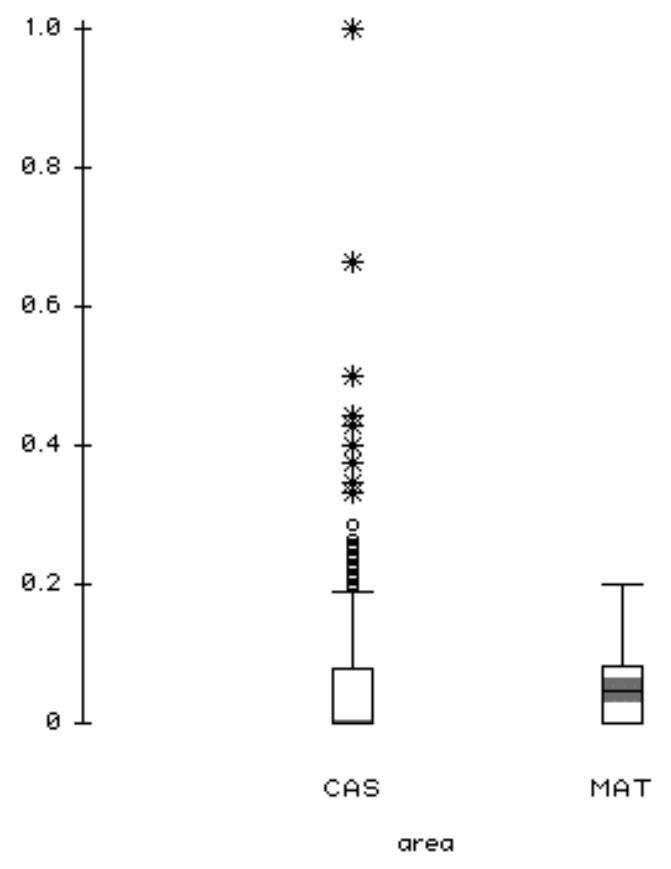

Figure 2: Attrition rates for math and non-math face to face course 'CAS' indicates non-math courses, 'MAT' indicates mathematics courses 
Table 2: Attrition rates for face to face courses, math versus non-math

\begin{tabular}{|c|c|c|c|}
\hline Group & Count & Mean & Std dev \\
\hline Non-math & 1189 & 0.05 & 0.1 \\
\hline Math & 57 & 0.05 & 0.06 \\
\hline
\end{tabular}

An analysis of variance indicated no significant difference between the attrition rates for math versus non-math face to face courses $(F=0.00005)$.

\section{Discussion}

Looking at the major research question (Is math more problematic online than other disciplines?) the attrition rate data definitely suggests this is so. The results provide relatively objective evidence of problems in math elearning. The large differences between average attrition rates for math versus non-math online courses ( 0.31 versus 0.18$)$ suggest there are serious problems with online math courses. That these differences between math and non-math attrition rates do not show up in face to face courses suggests that the problems involve an interaction between mathematics and the online learning modality.

But why are the attrition rates so much higher in online math courses? What are the problems? On the basis of previous qualitative studies (Smith, Ferguson \& Gupta, 2004; Smith \& Ferguson, 2003; Smith, Grackin, Ferguson \& Izubuchi, 2002) and the authors' experiences in an NSF funded project working with a large number of online math courses, we strongly suggest that the problems stem from the following issues.

The first issue is that the students in online courses are very different from the face to face students at universities. As mentioned earlier, online students often work full time and often have a poorer academic background. Also they are often returning to higher education after a long hiatus. They have may have forgotten much of their earlier math skills. This means they often lack the requisite background skills needed for mathematics. Because mathematics is cumulative in nature, with later methods building quite rigorously on earlier methods, mathematics is particularly unforgiving on gaps in background knowledge. Other disciplines are much more forgiving of weak student backgrounds. Because online students often have weaker academic backgrounds they struggle more with math than with other disciplines. Traditional face to face students at universities have stronger academic backgrounds and are more current with math skills. Consequently there is less differentiation in attrition between mathematics and other fields. 
Just as importantly, online learning environments are not well adapted to mathematics. The e-learning environment (Lotus Notes) used in the online math courses in study 1 has no direct support for math notation and diagrammatic communication. This makes it exceedingly hard for instructors and students to communicate back and forth with math notation. In some cases instructors have resorted to developing a code for math notation based on the characters available on the keyboard. For example, they would use " $x \wedge 2$ " to represent $x$ squared. Some students and instructors resort to faxing paper with hand written math notation back and forth. In some cases, instructors would incorporate other online tools or environments into their online courses to meet the needs of communicating math notation. However learning another online tool is a burden for many online students. In all these situations, the communication of math notation and diagrams does not have the level of "transparency" achieved by communication of text. When combined with other challenges of e-learning, such as physical isolation, fewer channels of communication (Smith, Ferguson \& Caris, 2002) and longer turn around time for answering questions, difficulties communicating with math notation and diagrams can be the "straw that breaks the camel's back," (Smith \& Ferguson, 2004).

The current pedagogical model of e-learning, emphasising totally asynchronous courses and threaded discussions, does not work well for mathematics courses (Smith \& Ferguson, 2004). Many e-learning organisations, such as SLN, emphasise that all online courses must be asynchronous, that is with no scheduled meeting times, either virtual or face to face. All communication is asynchronous, in a manner similar to listserv discussions and email. The rationale is that asynchronous elearning provides a "learn anytime, anywhere model" educational venue for people who are working full time and cannot schedule virtual meeting time. The rule of asynchronicity means that synchronous activities, such as chat board sessions scheduled at a specific time, cannot be graded or count for credit. The motivation may be worthy, but the turn around time for asynchronous question and answer is too slow for the difficulties students have with math (Smith \& Ferguson, 2004).

The current pedagogical model of e-learning also emphasises threaded discussions (asynchronous listserv style online discussions) as a major teaching and learning tool. Threaded discussions work well for many disciplines. For example, they work well for courses where students read and discuss papers. Threaded discussions are not very useful for math courses, where problem solving is more important than discussion.

Moreover, certain unique challenges of math make it much harder to teach online than many other disciplines. These include problem solving. In recent 
years there has been an increased emphasis on problem solving in mathematics education (Lester, Masingila, Mau, Lambdin, dos Santon \& Raymond, 1994). Math educators think it is critical that students not just be able to apply an algorithm for a particular class of problem, but that they be able to generalise and transfer problem solving (Schoenfeld, 1985, 1987; Stanic \& Kilpatrick, 1989).

Certain math education systems have evolved over time. Math instructors dynamically model face to face, real time, on the chalkboard, the problem solving process. Students ask questions. Then students work problems with copious instructor feedback. In the current asynchronous model, elearning documents are static and read like pages in a book. They lack the dynamism of an instructor working problems on a chalkboard (Smith \& Ferguson, 2004). In face to face classes, students often hand in their homework papers and the instructor can scribble feedback and corrections on the paper. With the problematic state of math notation and diagrams in e-learning, even this simple feedback cannot be taken for granted.

Previous studies of attrition in e-learning focused on issues such as student demographics (Morgan \& Tam, 1999; Carr, 2000), personal characteristics (self starters, self disciplined, familiar with e-learning, etc) (Roblyer, 1999; Wade, 1999) and experience of online instructors (Carr, 2000). The results of the current study, ie., large differences between average attrition rates for math versus non-math online courses (0.3 versus 0.18$)$, suggest that analysing attrition in e-learning by discipline could be a very productive research agenda.

\section{Conclusion}

Higher drop out rates provide conclusive evidence of problems with math in e-learning and triangulate with earlier qualitative studies. The authors suggest a number of explanations for why math may be harder to teach and learn online. First of all, the students in online courses are from a different population than face to face students at universities. Online students tend to be older students, working full time, often returning to higher education after a long break. Since mathematics is cumulative, with later methods building on earlier methods, mathematics is less tolerant of gaps in knowledge.

Secondly, the current models of e-learning and the common online course management systems (e-learning environments) do not effectively address the challenges of online math. Broad needs assessments and instruction design efforts, which transcend the current dogma of e-learning, need to be initiated. 


\section{Endnote}

A version of this article was presented at CIT2005 (SUNY Conference on Instructional Technologies), Binghamton University, Binghamton NY, 2326 May 2005, with abstract only publication.

http: / / cit.suny.edu/ cit2005/ abstract-full.pdf

\section{References}

Boshier, R. (1990). Socio-psychological factors in electronic networking. International Journal of Lifelong Education, 9(1), 49-64.

Carr, S. (2000). As distance education comes of age, the challenge is keeping the students. The Chronicle of Higher Education, February 11, A39-41.

Cohen, J. (1988). Statistical power analysis for the behavioral sciences (2nd ed.). Hillsdale, NJ: Erlbaum.

Lester, F.K.Jr., Masingila, J.O., Mau, S.T., Lambdin, D.V., dos Santon, V.M. \& Raymond, A.M. (1994). Learning how to teach via problem solving. In D. Aichele \& A. Coxford (Eds), Professional development for teachers of mathematics, (pp. 152-166). Reston, Virginia.

Leventhall, L. (2004). Bridging the gap between face to face and online maths tutoring. Paper presented at the International Congress of Mathematics Education-10, Copenhagen, Denmark, July 2004. [verified 9 Aug 2005] http:/ / dircweb.king.ac.uk/papers/Leventhall_L.H.2004_242915/leventhall_ICME10.pdf

Morgan, C.K. \& Tam, M. (1999). Unraveling the complexities of distance education student attrition. Distance Education, 20(1), 96-108.

Phipps, R. \& Merisotis, J. (1999). What's the difference? A review of contemporary research on the effectiveness of distance learning in higher education. Council for Higher Education Accreditation.

Roblyer, M. D. (1999). Is choice important in distance learning: A study of student motives for taking Internet based courses at the high school and community college levels. Journal of Research on Computing in Education, 32(1), 157-171. [verified 9 Aug 2005; abstract only] http:/ / www.iste.org/inhouse/ publications / jrte/32/1/abstracts/roblyer.cfm?Section=JRTE_32_1

Schoenfeld, A. (1985). Mathematical problem solving. New York: Academic Press.

Schoenfeld, A. (1987). Cognitive science and mathematics education. Hillsdale, NJ: Erlbaum Assoc.

Shea, P., Swan, K., Fredericksen E., \& Pickett, A. (2001). Student satisfaction and reported learning in the SUNY Learning Network. In Elements of quality online education, Volume 3 in the Sloan-C series, The Sloan Consortium New York.

Smith, G. G. (2005). Problems with e-learning we can't ignore: One size does not fit all. Proceedings of ED-MEDIA 2005: World Conference on Educational Multimedia, Hypermedia \& Telecommunications, Montreal, Canada. 
Smith, G.G. \& Ferguson. D. (2004). Learning math problem-solving in online courses. Proceedings of E-Learn 2004: World Conference on E-Learning in Corporate, Healthcare $\&$ Higher Education, Washington, DC.

Smith, G.G. \& Ferguson. D. (2003). Two-way online communication of diagrams and math notation: Implications for instructional design of e-learning math courses, Proceedings of E-Learn 2003: World Conference on E-Learning in Corporate, Healthcare $\mathcal{E}$ Higher Education, 735-738.

Smith, G.G., Ferguson, D. \& Caris, M. (2002). Teaching online versus face-to-face. Journal of Educational Technology Systems, 30(4), 337-364.

Smith, G.G., Grackin, J.A., Ferguson, D. \& Izubuchi, R. (2002). Math and distance learning threaded discussions. Proceedings of ED-MEDIA 2002: World Conference on Educational Multimedia, Hypermedia E Telecommunications, Denver, Colorado, 3, 1819-1824. [verified 16 Aug 2005] http:/ / www.linksystems.com/ext_PNqUdT9CiqIAADkeBh4/GlennSmithEDMedia42902.pdf

Smith, G.G., Ferguson, D. \& Gupta, S. (2004). Diagrams and math notation in elearning: Growing pains of a new generation. International Journal of Mathematical Education in Science and Technology, 35(1), 681-695.

Stanic, G. and Kilpatrick, J. (1989). Historical perspectives on problem solving in the mathematics curriculum. In R.I. Charles \& E.A. Silver (Eds), The teaching and assessing of mathematical problem solving, (pp. 1-22). Denver, Colorado: National Council of Teachers of Mathematics.

Swan, K. (2001). Immediacy, social presence, and asynchronous discussion. In Elements of quality online education, Volume 3 in the Sloan-C series, The Sloan Consortium New York.

Thompson, E (1997). Distance education drop-out: What can we do? In R. Pospisil \& L. Willcoxson (Eds), Learning through teaching, p324-332. Proceedings of the 6th Annual Teaching Learning Forum, Murdoch University, February 1997. Perth: Murdoch University. http: / / lsn.curtin.edu.au/tlf/tlf1997/ thompson.html

Dr Glenn Gordon Smith, College of Education, EDU162, University of South Florida, 4202 E. Fowler Avenue, Tampa FL 33620-5650, USA.

Email: gsmith@coedu.usf.edu Web: http:/ / www.coedu.usf.edu /

Professor David Ferguson, Department of Technology and Society, Stony Brook University, Stony Brook, NY 11794. Web:

http: / / ws.cc.stonybrook.edu/est/ people/fp/ferguson.html 